\title{
Relações de gênero e a questão racial em Chove nos campos de Cachoeira, de Dalcídio Jurandir
}

\author{
Gender relations and the racial issue in Chove nos campos de Cachoeira, \\ by Dalcídio Jurandir \\ Priscila Garcia BALIEIRO* \\ Universidade Federal do Sul e Sudeste do Pará (UNIFESSPA) \\ José Rosa dos SANTOS JÚNIOR** \\ Instituto Federal de Educação, Ciência e Tecnologia do Pará (IFPA), \\ Universidade Federal do Sul e Sudeste do Pará (UNIFESSPA)
}

RESUMO: O presente artigo visa abordar questões de gênero, discutindo a representação da mulher negra, a partir da personagem D. Amélia da obra Chove nos Campos de Cachoeira (1991) de Dalcídio Jurandir. As análises das falas dessa personagem e a fala dos outros sobre ela mostram a relação consigo e com o outro e, desse modo, verifica-se como é forjada a alteridade feminina na referida obra. Debruçamos sobre o que essa personagem mulher, negra e pobre nos diz sobre as questões de gênero e de subalternidade no contexto amazônico. As reflexões, aqui empreendidas, estão fundamentadas nos pressupostos teóricos cunhados por Akotirene (2019), Alzandúa (2000), Davis (2016), Fanon (2008), Gonzalez (2020), dentre outros.

PALAVRAS - CHAVE: Literatura das Amazônias. Gênero. Raça.

\footnotetext{
* Graduada em Letras - Língua Portuguesa pela Universidade Federal do Pará (2009); Especialista em Linguagem e Educação: uma abordagem textual, discursiva e variacionista pela UFPA/Cametá, (2012); Especialista em Políticas públicas para a juventude - PROJOVEM Urbano pela Universidade do Estado do Pará - UEPA (2012) e Mestranda em Letras pelo Programa de Pós-Graduação em Letras da Universidade Federal do Sul e Sudeste do Pará (UNIFESSPA). Marabá-Pará.E-mail: priscilagbalieiro@ yahoo.com.br

** Doutor em Literatura e Cultura pelo Programa de Pós-graduação em Literatura e Cultura do Instituto de Letras da Universidade Federal da Bahia - UFBA. Professor do Instituto Federal de Educação, Ciência e Tecnologia do Pará - IFPA, Campus Marabá Industrial. Professor Permanente do Programa de PósGraduação em Letras (POSLET) do Instituto de Linguística, Letras e Artes da Universidade Federal do Sul e Sudeste do Pará (UNIFESSPA). Marabá-Pará.E-mail: juliteratta @gmail.com
} 
ABSTRACT: This article aims to address gender issues, discussing the representation of black women, based on the character D. Amélia in the work Chove nos Campos de Cachoeira (1991) by Dalcídio Jurandir. The analysis of this character's speech and the speech of others about her, show the relationship with herself and with the other and, in this way, it is verified how the feminine alterity is forged in the referred work. We analyze what this female, black and poor character has to tell us about the issues of gender and subordination in the Amazonian context. The reflections undertaken here are based on theoretical assumptions coined by Akotirene(2019), Alzandúa (2000), Davis (2016), Fanon (2008), Gonzalez (2020), among others.

KEYWORDS: Literature of the Amazon. Gender. Breed.

\section{Introdução}

O presente estudo se propõe analisar a representação do feminino na obra literária Chove nos Campos de Cachoeira (1991), de Dalcídio Jurandir, com vistas à compreensão das relações de gênero e de raça que se tecem no contexto da Amazônia e que se fazem presentes na obra de Dalcíd io. A abordagem datemática de gênero, de raça, mas também de classe, por meio da figura do feminino, traz para a cena acadêmica, as problematizações acerca da literatura de um escritor paraense que, a despeito da profundidade temática e dos tensionamentos sugeridos, ainda hoje, permanece desconhecida do grande público.

Chove nos campos de Cachoeira nos oferece uma perspectiva fértil para esta análise, uma vez que o autor mobiliza uma complexa rede existencial na construção da personagem D. Amélia, revelando nuances de sua vida, construções discursivas e lutas, ainda que silenciosas, que elaboram profundas reflexões sobre a condição da mulher na sociedade. Veremos como o marcador social atravessa o marcador raça e o marcador gênero, e quando o primeiro interpela, mais potentemente, a condição do ser mulher, os obstáculos se erguem ainda mais imperiosos.

As descrições, as interpretações e as análises da personagem D. Amélia estão fundamentadas nos pressupostos teóricos de raça e de gênero e evocam grandes intelectuais que se dedicaram ao ofício de pensar e de debater a condição da mulher negra, como Ângela Davis (2016), bell hooks (2019) e Lélia Gonzalez (2020). Tais pressupostos 
possibilitaram analisar os discursos da personagem, mas também os discursos elaborados sobre ela, o que revela a relação consigo mesma e com os outros.

Quais são os discursos sobre as questões de gênero e de raça existentes nas falas da personagem D. Amélia? E dos outros sobre ela? Essas indagações serão problematizadas, em contraponto com a observância das condutas e dos paradigmas seculares que insistem em demarcar o lugar da mulher na sociedade e como tais modelos - calcados no patriarcalismo - persistem, e são reproduzidos culturalmente nas diversas classes ou grupos sociais, com maior ou menor ocorrência e intensidade. O estudo apresenta, ainda, a composição das personagens femininas, a fim de perceber e de tensionar o que elas dizem sobre as questões de gênero e de raça, calcadas na inegociável alterid ade feminina.

\section{D. Amélia: relações de gênero e a questão racial no romance Chove nos Campos de Cachoeira}

A protagonista do romance nos é apresentada, desde o início, como uma mulher firme e tendo uma história que atravessa a segregação social, racial e de gênero. Vejamos:

D. Amélia era uma pretinha de Muaná, neta de escrava, dançadeira de coco, nas Ilha s, cortando seringa, andando pelo Bagre, perna tuíra, a panhando açaí, gapuiando, atirada a trabalho como um homem. Viu â mãe morrer de uma recaída de papeira, sem recursos, a palhoça caindo, a prostituição, o pai golado dizendo besteiras na hora do enterro, mas Amelinha firme não se deu por achada. Tinha perdido um filho levado pelo sucuriju nas Ilhas. (JURANDIR, 1991,p. 37).

D. Amélia é uma personagem que se destaca, no âmbito narrativo, por possuir inúmeras qualidades e por adotar uma postura de enfrentamento ao preconceito sofrido por ser uma mulher negra, e que se calca em várias camadas de subalternidades. Filha de povos escravizados, nascida na pobreza, é detentora de conhecimentos culinários e uma beleza que chama a atenção do Major Alberto, no entanto o Major convida D. Amélia para morar com ele, por conta da sua habilidade como cozinheira e cuidadora. A despeito dessa habilidade reducionista, nos é apresentado uma mulher forte que, vivenciando todas 
as mazelas que lhe foram impostas, mantém-se firme, com uma força que as mulheres, em sua condição, são obrigadas a ter, como garantidora de suas próprias vidas.

Vale ressaltar que D. Amélia, em Muaná, trabalhava na lavoura "como um homem", o que nos permite relacionar essa condição da personagem com "O legado da escravidão”, em que Angela Davis, no seu livro “Mulheres, raça e classe” (2016), traz à baila, ao relacionar esse legado com a escravidão nos Estados Unidos. D. Amélia reatualiza as condições de seus ancestrais escravizados, introduzidos na Amazônia, no final do século XVII, para reforçar a política colonizadora da coroa portuguesa. Segundo Angela Davis, (2016, p.18), "tal qual a maioria dos escravos, a maior parte das escravas trabalhavam na lavoura" e isso, como vimos anteriormente, é descrito na personagem protagonista, trabalhand o nos seringais, na coleta de açaí, exercendo todo tipo de trabalho extrativo nas matas de Muaná.

Essa é a mulher que Major Alberto, após ficar viúvo, convida para ir morar consigo em Cachoeira, pois D. Amélia é mulher trabalhadora e honesta, habilidosa na cozinha e com uma beleza invejável. Isso lhe propiciou ocupar uma função de "esposa". Ao analisar o acordo entre eles, é possível depreender que o interesse de Major Alberto, na consumação do ato, tem como princípio maior o seu próprio bem-estar e não aparenta, nem um mais remoto desejo "revolucionário" de quebrar paradigmas sociais secularizados.

Podemos pensar que Major Alberto tem por intenção obter os serviços em casa de uma mulher negra, para servi-lo em todos os "cômodos", sem as cobranças da sociedade por um casamento hegemônico eurocêntrico. E faz isso sob a proteção da ausência do matrimônio com D. Amélia, ou seja, o convite foi formalizado como uma oferta de trabalho. Tentando não revelar qualquer tipo de pretensão, num tom de descaso, o Major diz: "Vais, e se te acostumares..." (JURANDIR, 1991, p. 37). E apesar de ter consciência do que irá enfrentar, nesse novo lugar, ela decide aceitar o convite:

\footnotetext{
Amélia resolveu-se:

- Ele me convidou. Não me assanhei para o lado dele. Tenho a consciência tranquila de que não fiz nada para ele me convidar. Se vou é para trabalhar para ele. Sou uma pobre. Cozinho, lavo, engomo e depois é a minha sorte ir agora com ele. Sou mulher para trabalhar. Se a minha sorte está marcada pra ficar com ele, fico. (JURANDIR, 1991, p. 37).
} 
Observa-se, nessa atitude de D. Amélia, as internalizações psíquicas abordadas por Frantz Fanon (2008) em Pele negra, máscaras brancas. Na respectiva obra, mais especificamente no capítulo "A mulher de cor e o branco”, Fanon analisa Mayotte Capécia, a partir do romance autobiográfico “Je suis Martiniquaise”. Diferente de D. Amélia, a narradora casa-se com um branco pelas características hegemônicas enraizadas no ocidente, deixando claro que o ama por tais características.

Em relação à personagem dalcidiana, as circunstâncias do acordo são do tipo: a subserviência e subjugação da mulher, que a partir de então, viverá um contrato de servidão ao seu homem. E isso é muito bem entendido por D. Amélia: “[...] Se vou é para trabalhar para ele. Sou uma pobre. [...] Sou mulher para trabalhar. Se a minha sorte está marcada pra ficar com ele, fico" (JURANDIR, 1991, p. 37). A postura da mulher negra nos dois romances reforça a episteme feminina de que "As mulheres negras têm umbigos diferentes e seus cordões foram cortados em contextos diferentes" (SILVA, 2005 apud AKOTIRENE, 2019, p. 45), mas que deixam traumas que se reverberam na realidade e na ficção.

D. Amélia é descrita a partir de cor, das formas dos cabelos, através das suas risad as e o modo de lidar com as dificuldades em que vive, principalmente, o preconceito racial que permanentemente lhe afeta. Sua vida é motivo de fofocas entre os moradores de Cachoeira e revelam o preconceito social em relação à união de uma negra com um branco. Observemos:

[...] Aquela preta passa bem na casa dela. Afrontando a sociedade com aquela preta. Uma preta. Rapariga. O que me mete uma raiva é a gente se casar, fazer tudo pra manter a virtude da gente e no cabo de tudo, a miséria vem para cima de nós e não para cima dos que vivem na a masiagem, fora da lei, da sociedade. São felizes. Olha a Bita. Se ela quisesse se amasiar já tinha se amasiado. E estava bem na fartura. E a gente se casa no católico, na lei, faz tudo para viver na sociedade e a fome roendo a gente. Seu Cristóvão, não passo ma is de fome. Tenho um buraco no estômago. Tenho vontade assim de comer uma maça, um figo, ter um prato de filé, comer um peru! Eu quero comer essas coisas, Cristóvão! Pensa que lá na casa de siá Amélia, pensa que aquela preta não come maça? Pensa que ela não come uva? Come maçã, come uva. Quando chega semana santa come bacalhau! A preta. Bacalhau. Olha, que eu, uma 
criatura acostumada com todas essas coisas boas, sou obrigada a comer jiju! A comer este naco de carne velha e magra todo dia, Cristóvão? Tu não tens pena de mim, Cristóvão? (JURANDIR, 1991, p. 70 -71).

Essa fala é de D. Dejanira, matriarca de uma das principais famílias falidas do vilarejo. É possível observar sua insatisfação pela posição social que D. Amélia, mulher negra, conquistou em Cachoeira, mesmo sem se casar no civil e no religioso como apregoam os princípios hegemônicos eurocêntricos para o matrimônio, uma vez que ela tensionou o paradigma imposto pela sociedade para sua condição social e racial, ao se tornar integrante da sociedade cachoeirense. Nos discursos da narrativa dalcidiana, fica evidente que o julgamento das mulheres cachoeirenses, em relação à D. Amélia, não se dava por causa da classe social de Amélia, vinda de Muaná, mas pelo fato de ser negra.

Os homens de Cachoeira também teciam comentários maliciosos e racistas sobre a escolha afetiva do Major Alberto. A seguir, veremos a fala do Doutor Campos, Juiz substituto de Cachoeira, em diálogo com amigos no mercado:

\section{Dr. Campos falava:}

— Major Alberto não gosta de café puro nem de leite simples. E sim, café com leite, com mais café que leite. Fica é mais gostoso e eu sei por experiência. Você, Salu, aqui numa confidência, não sabe o quanto me dói ter a minha senhora como é. Muito branca, a pesar de muito culta, mas como me enterro, por exemplo, na Maguá, na Aurélia! (JURANDIR, 1991,p. 38).

Nesse comentário, é possível ver a única condição atribuída à mulher negra pela sociedade, naquele período: ser objeto sexual, proporcionar prazer ao homem. No entanto, D. Amélia foi convidada por Major Alberto com a finalidade de ser sua cozinheira. Um relacionamento entre classes sociais e grupos raciais diferentes começava; a relação entre D. Amélia e Major Alberto passa a ser o grande incômodo na pequena cidade de Cachoeira.

Além do povo cachoeirense, em Muaná, a protagonista também é vítima da discriminação racial vinda das filhas do primeiro casamento do Major Alberto. As falas de suas enteadas expondo comentários de racismo e ódio são recorrentes: "Era uma pretinha. Se ainda fosse pessoa de qualidade..., mas uma pretinha de pé no chão! Quem 
logo! Seu pai estava de cabeça virada para uma negra. Uma cortadeira de seringa!" (JURANDIR, 1991, p. 37).

O racismo deixa sequelas difíceis de esquecer. De acordo com Fanon (2008), o ego da pessoa que passa por traumas como esse, se retrai e causa prejuízos intersubjetivos, o que faz com o sujeito negro, a sujeita negra desenvolva um complexo de inferioridade e mais que isso:

O problema é saber se é possível ao negro superar seu sentimento de inferioridade, expulsar de sua vida o caráter compulsivo, tão semelhante ao comportamento fóbico. No negro existe uma exacerbação afetiva, uma raiva em se sentir pequeno, uma inca pacidade de qualquer comunhão que o confina em um isolamento intolerável. (FANON, 2008,p.59)

Amélia, a moradora de Muaná, na dúvida entre ir ou não morar com o Major Alberto, é encorajada pelas amigas: “- V Vai, sua besta! Só por que és preta? Mas és uma preta nova e limpa. És caprichosa. Porque tens esse gênio pensam que andas defogo aceso para homem” (JURANDIR, 1991, p.37). Nota-se, também, que as amigas de Amélia reforçam ainda mais o estereótipo às mulheres negras, que quando jovens, seus corpos são objetificados e que o preto, no imaginário racista, é sinônimo de sujeira. Suponho que Amélia percebe sua condição objetificada, "tenta romper", ao não aceitar de imediato o convite de Major Alberto. Mas suas camadas de subalternidades (mulher, negra, pobre, amazônida) a sufocam, e ela é incapaz de resistir pelas condições impostas a ela.

Em meio aos comentários mald osos e racistas, da "união" do casal, nascem dois filhos: Alfredo e Maria (Mariinha). Mas o primogênito destaca-se no romance por viver uma crise de identidade, o que o faz sentir vergonha deD. Amélia, devido a sua cor. Desse modo, podemos ver que a questão racial provoca um tensionamento e perturba os pensamentos de Alfredo, ou seja, a questão racial é sempre um ponto colocado em tese. Evidência comprovada pelos questionamentos de Alfredo:

\footnotetext{
Alfredo achava esquisito que seu pai fosse branco e sua mãe preta. Envergonhava-se porter de achar esquisito. Mas podia a vila toda caçoar deles dois se saíssem juntos. Causava-lhe vergonha, vexames, não sabia que mistura de sentimentos e faz-de-conta. Por que sua mãe não nascera ma is clara? Elogo
} 
sentia remorso de ter feito a si mesmo talpergunta. Logo sentia remorso de ter feito a si mesmo tal pergunta.(JURANDIR, 1991, p. 4).

Alfredo deseja que sua mãe seja branca como as demais senhoras de Cachoeira, achava que sua cor não era comum, pois despertava em si um sentimento de inferioridade e de discriminação nos moradores da cidade. O menino se perguntava, permanentemente, o porquê de sua mãe possuir aquela cor. Logo em seguida, e em contrapartida, habitava em seu coração um sentimento de vergonha porque se tratava de sua mãe, pessoa pela qual possuía o mais profundo sentimento de amor e a mais intensa afetividade. Nota-se que a temática de Fanon (2008), não é condição apenas de D. Amélia, mas do filho também.

Alfred permanece como um personagem que vive permanentemente um dilema entre a construção de sua identidade racial versus os conflitos de sua posição social. Seu cotidiano trazia-lhe esses conflitos, toda vez que passava por uma situação de preconceito e através de sua imaginação, ele criava uma situação de fuga da realidade na esperança de que esses problemas sociais e raciais viessem a ser resolvidos como num passe de mágica: “Quantas vezes não fez D. Amélia, branca, casada com o Major, cheia de cordões de ouro no pescoço, Alfredo às vezes se aborrecia ou tinha pena que fosse moreno e sua mãe preta" (JURANDIR, 1991, p. 144).

A neurose psicanalítica manifestada em Alfredo mostra o quanto é complexo esse sentimento nos povos racializados. Alfredo desde criança não toma café para não ficar preto, od eia ser chamado de branco e, da mesma forma, odeia ser chamado de preto. Sobre essa questão, Fanon assevera:

\footnotetext{
O preto, no seu comportamento, a ssemelha-se a um tipo neurótico obsessional, ou, em outras palavras, ele se coloca em plena neurose situacional. Há no homem de cor uma tentativa de fugir à sua individualidade, de aniquilar seu estar-a qui. Todas as vezes que um homem de cor protesta, há a lienação. Todas as vezes que um homem de cor reprova, há a lienação. (FANON, 2008, p.66)
}

Por meio das ações dessa personagem-criança, nota-se, os males que o racismo lhe causou, e que a segregação racial produz traumas e faz com que as pessoas afetadas se sintam inferiores, causando-lhes uma revolta social e, no caso deste personagem, 
vergonha da própria mãe. No romance, Alfredo se revolta diante dessa situação, vive conflitos constantes, interioriza tudo, lhe causando sofrimentos e descontentamento ao ponto de questionar o porquê de sua mãe não ser branca. Com base em Fanon (2008), poderíamos dizer que um mecanismo de internalização da norma branca atuava permanentemente no corpo e pensamento de Alfredo, afetando-lhe profundamente em todas as fases de sua vida, levando-o a se isolar do mundo, com um caroço de tucumã.

A esse respeito, Louro (1997) apud Azeredo (1994) fala num tom parecido, quando discute porque "em um país racista e desigual como o Brasil" damos tão pouca atenção à questão racial, seja em nossos trabalhos teóricos, seja em nossas práticas. Analisando as produções acadêmicas nacionais e internacionais, Louro nos diz:

\footnotetext{
Minha intenção ao tentar estabelecer uma conversa entre essas diversa s formas de fazer teoria são explicitar minha aposta na ideia de que complexificar a categoria gênero — historicizá-la e politizá-la —, prestando a tenção em nossa análise a outras relações de opressão, pode nos abrir caminhos sequer imaginados ainda de uma sociedade mais igualitária. Para tanto, é preciso considerar gênero tanto como uma categoria de análise quanto como uma das formas que relações de opressão a ssumem numa sociedade capita lista, racista e colonialista. (LOURO, 1997, p. 55).
}

De acordo com a autora, é necessário mais atenção às categorias subalternizadas, seja por meio da pesquisa, seja por meio das práticas pedagógicas. E, como Akotirene (2019), não se propõe hierarquizar categorias como objeto epistêmico, afinal existem diferentes mulheres com lutas e objetivos incomuns, mas todas em busca de igualdade de direito, sem esquecer que umas são mais obliteradas que outras, por uma sociedade etnoeuro-logo-falocêntrica.

Outra questão que não podemos deixar de mencionar são os vocábulos usados, de modo explícito, para se referir à D. Amélia, reforçando, assim, o racismo acometido contra a mulher negra: "molambenta", "pé no chão", "rapariga". A esse respeito é esclarecedor o comentário da intelectual decolonial bell hooks, em sua obra Olhares negros: raça e representação (2019), que trata de questões feministas que fraturam o mundo contemporâneo hegemônico: 


\begin{abstract}
Bombardeadas por imagens que representa $m$ corpos de mulheres negras como descartáveis, as mulheres negras absorveram esse pensamento passivamente ou resistiram a ele com veemência. A cultura popular oferece exemplos incontáveis de mulheres negras se apropriando de e explorando "estereótipos negativos" para garantiro controle sobre a representação ou, no mínimo, colher seus frutos. (HOOKS, 2019, p.136).
\end{abstract}

De acordo com a autora, cria-se, por meio de estereótipos, imagens negativas que representam os corpos de mulheres negras para firmar uma oposição entre as mulheres negras e as mulheres brancas, baseada unicamente em diferenças fenotípicas para, assim, criar o padrão eurocêntrico.

No artigo Diversidade Cultural: Inclusão, Exclusão e Sincretismo, Monteiro (1996) apresenta seu posicionamento sobre diversidade cultural, mostrando que a cor da pele consistiu num parâmetro de sujeição do ser humano às formas exploratórias e espoliadoras da sua liberdade e de seus direitos e as sequelas dessa brutal privação desde o período escravista. A autora explicita o fato de que as diferenças culturais traduzem-se em problemas e que a sociedade brasileira aind a maquia uma postura, através da qual a disseminação de ideias preconceituosas e discriminatórias ganha contornos e visibilidade, no corpo social, caminhando no sentido inverso ao do respeito à diferença.

Uma vez que a Constituição brasileira de 1988 traz a igualdade como princípio, é necessário se atentar para o fato de que a diferença não se opõe ao princípio da igualdade, a igualdade coexiste na diferença. Ainda de acordo Monteiro (1996), o reconhecimento da pluralidade e da diferença permite o respeito à individualidade, bem como a garantia da legitimidade social e política do grupo no qual os sujeitos afirmam seu pertencimento.

A esse respeito, no âmbito da narrativa, podemos observar a importância da valorização cultural para que Alfredo manifestasse seu orgulho de pertencer à cultura afrodescendente, após conhecer sua cultura por meio das danças, das músicas, das narrativas orais: "De qualquer modo, o despertar de Alfredo para a valorização da cor da mãe só vai aparecer com maior definição no terceiro romance de Dalcídio, Três casas e um rio" (LEAL, 2014, p. 103).

Leal (2014) reporta-se a Dalcídio e descreve o momento quando, no meio do salão, D. Amélia começa a cantar modinhas, acompanhada de um maracá indígena com 
um pano azul na cintura, canta e dança em passos lentos conduzindo a festa com liderança e respeito. Nesse momento, Alfredo percebeu que a mãe estava no centro das atenções, seus conhecimentos lúdicos e mágicos lhe deram autoridade entre os participantes de um boi-bumbá e, a partir daí, começou a valorizar sua identidade racial, pois conheceu a riqueza e a beleza que existiam em sua cultura:

\footnotetext{
Sua mãe cantava a ssim com essa quentura humana, essas lembranças e ele não sabiam que quando ela cantava para adormecê-lo, era com todo esse peso de sofrimento, de saudade. Por isso achava aquele encanto nas modinhas de sua mãe. Vinham da carne, da sua experiência, de sua aventura nos seringais, do filho morrendo debaixo do jirau e sucuriju levando, daquelas febres sombrias e fabulosas das Ilhas. (JURANDIR, 1991, p. 79).
}

D. Amélia encena uma tradição inscrita na cultura com marcas singulares de um modo de vida e uma característica presente em muitas mulheres, não somente no contexto regional da Amazônia, mas em mulheres de diferentes países e nações que lutam contra o "genocíd io cultural" e resistem, por meio de sua memória e de suas práticas culturais, ao poder e à imposição hegemônica que insiste em defender uma única história e uma única cultura.

Segundo a filósofa e antropóloga Lélia Gonzalez (2020, p.40), "no período que imediatamente sucedeu à abolição, nos primeiros tempos de "cidadãos iguais perante a lei”, coube à mulher negra arcar com a posição de vigia mestra de sua comunidade”. Esse legado incutido às mulheres de cor é notório em D. Amélia, uma vez que ela assume uma posição de mãe da comunidade cachoeirense, doa alimentos e remédios aos mais pobres, cuida dos doentes, ajuda a parteira e, muitas vezes, atravessa chuvas e lamas, em plena madrugada, para socorrer quem precisa de suas especialidades, "sabia curar bem uma garganta. Metia o dedo enrolado de algodão, ensopado de mel e limão assado na goela dos meninos e acabava a inchação e a dor. Tỉnha um dedo benzido" (JURANDIR, 1991, p.46). No entanto, mesmo sendo um ser humano benevolente, à disposição para ajudar os mais necessitados, sempre que seu nome entra nas rodas de conversas, ou no pensamento dos habitantes da cidade, o tema é sempre o mesmo: o incômodo dos moradores com a cor de D. Amélia, principalmente por conta da união com um branco, união essa que se 
fez "sem os laços sagrados do matrimônio", imperiosamente fundamentais na época, o que aumenta o seu estigma social: além de mulher, negra, pobre, é amásia.

Como mãe, foi capaz de proteger seu filho da morte ao salvá-lo de um acidente dentro do poço, pois já havia perdido outro filho afogado. Nota-se, ainda, que Amélia teve a sua maternidade "afogada" junto com o filho primogênito que não pode salvar do "sicuriju" e, quando percebe que seu segundo filho, o Alfredo, poderia ter o mesmo destino, desespera-se e age num impulso para salvá-lo da queda no poço. O propósito não é resgatar em si mesma a perda dofilho, mas sim a perda da mãe que não conseguiu salvar o próprio filho. No momento em que salva a vidade Alfredo, Amélia inicia o seu processo de redenção: "daí em diante parecia mais dela" (JURANDIR, 1997, p.02), como se até aquele momento ela não fosse uma mãe completa e oferecesse, ao filho, apenas uma maternidade parcial:

\footnotetext{
Quando sua mãe a parecia com a cuia e o algodão para lavaras feridas, Alfredo se amolecia na rede num quase desejo de morrer, morrer devagarinho com o braço de sua mãe sob a sua cabeça. Aquilo era também da febre. Mas de súbito um ímpeto de chorar alto, de gritar para espantar aquele desejo sem forma. Vontade de batero pé para a mãe embrulhar-se na rede, repelindo o curativo, não queria nada. D. Amélia nascera com aquelas mãos para tratar feridas. E agora Alfredo sabe que nem essas mãos nem as grandes chuv as em março cura a marca das feridas (JURANDIR, 1991,p. 04).
}

Há também uma relação de ética direcionada para a formação do filho, ao demonstrar preocupação com a educação e o futuro do mesmo, uma vez que, naquele lugar, o futuro de Alfredo, sem estudos, não era promissor. Ela via a necessidade dele prosseguir seus estudos na capital. E, para sua vontade se concretizar, insistiu e enfrentou seu marido, o Major Alberto, a fim de permitir a ida do menino para prosseguir seus estudos em Belém: "Major Alberto continua indiferente ao seu futuro, mas dona Amélia se queixa que Alfredo acaba se perdendo em Cachoeira. - Mas eu boto meu filho em Belém" (JURANDIR, 1991, p.147).

Em Chove nos Campos de Cachoeira, a figura do feminino é o elemento de ligação entre Alfredo e a continuação dos estudos e de sua busca pela formação na Capital. Apesar de D. Amélia, mulher seringueira, não possuir grande instrução escolar é ela quem se preocupa com a formação do filho, uma vez que o Major Alberto exercia 
cargo público, tinha instrução e poderia incentivar Alfredo nos estudos, mas isso não acontece. No romance, a figura do feminino é quem tem o poder de ação e, com a sua insistência, ela realiza seu desejo de mãe e, com isso, atende ao pedido de formação solicitado permanentemente por Alfredo:

\footnotetext{
Major Alberto continua indiferente a o seu futuro, mas dona Amélia se queixa que Alfredo acaba se perdendo em Cachoeira. - Mas eu boto meu filho em Belém. Seu Alberto não se mexe, mas vai ver se não arrumo uma casa para Alfredo ficar... Só eu me resolvendo. Senão... (JURANDIR, 1991,p.45).

Com Eutanázio parado em casa, a sua angústia se espalhava e contaminava o chalé. Major tinha, às vezes, discussões terríveis com dona Amélia. Ela se tornava incoerente, se desdizia, se queixava, dizia que nem que fosse vender tacaca em Belém, mas Alfredo tinha de ir pa ra o colégio. (JURANDIR, 1991, p.147).
}

Vemos, na construção dessa personagem, as questões do feminino tecendo as tramas das relações familiares. Acerca dessa tessitura, Lélia Gonzalez afirma que a mulher negra "foi o sustento moral e a subsistência dos demais membros da família. Isso significou que seu trabalho físico foi duplicado, uma vez que era obrigada a se dividir entre o trabalho duro na casa da patroa e as suas obrigações familiares" (GONZALEZ, 2020, p.40).

\section{Considerações finais}

Chove nos campos de Cachoeira performatiza a condição da mulher negra, subalternizada por uma sociedade forjada pelos ditames da herança colonial e escravagista e que reproduz, por meio de mecanismos simbólicos poderosos, os mais diversos ordenamentos sociais que, secularmente, construíram um lugar para a mulher negra: amamentar os filhos dos seus senhores, procriar, limpar, cuidar, lavar.

D. Amélia, ainda que encene esses lugares do limpar, do cuidar e do lavar, movimenta-se para um lugar de transgressão irreversível: ousou ao "se juntar" com um homem branco e ocupante de uma posição de destaque na sociedade cachoeirense, e não 
sucumbiu diante das investidas dos olhares, dos comentários e de toda a manifestação do racismo estrutural que modula as relações sociais.

Ser mulher, negra, periférica, porque amazônica, é ocupar, três vezes, as margens dos centros de poder, de decisão, de fala. A despeito dessa constatação, D. Amélia é a responsável pela organização do seu microcosmo e, ao seu modo, consegue intervir nas decisões do núcleo familiar, conquistando, mesmo que de contrabando, um poder microfísico, de acordo com o que apregoa Michel Foucault (2013). D. Amélia, dessa forma, ocupa um lugar de centralidade na narrativa e responsável pelos tensionamentos mais profícuos que se dão na construção da subjetividade do filho Alfredo, mas também de diversas outras personagens não imunes à presença de uma mulher negra em um lugar precário de centralidade.

\section{REFERÊNCIAS}

AKOTIRENE, Carla. Interseccionalidade. São Paulo: Pólen, 2019

ALZANDÚA, Gloria. Falando em línguas: uma carta para as mulheres escritoras do terceiro mundo. In: Revista Estudos feministas. №1, vol.8, 2000.

DAVIS, Angela. Mulheres, raça e classe. Trad. Heci Regina Candiani. São Paulo: Boitempo, 2016.

FANON, Frantz. Pele negra, máscaras brancas. Trad. Renato da Silveira. Salvador: EDUFBA, 2008.

FOUCAULT, Michel. Microfísica do Poder. Organização, introdução e revisão técnica de Renato Machado. São Paulo: Graal, 2013.

GONZALEZ, Lélia. Por um feminismo afro-latino-americano: ensaios, intervenções e diálogos. Rio de Janeiro, 2020.

JURANDIR, Dalcídio. Chove nos Campos de Cachoeiras. Belém: Cejup, 1991.

HOLANDA, Sérgio Buarque de. Raízes do Brasil. São Paulo: Companhia das Letras, 1995.

HOOKS, bell. Olhares negros: raça e representações. Trad. Stephanie Borges. São Paulo: Elefante, 2019.

LEAL, Luiz Augusto Pinheiro. Gladiadores de escassa musculatura: sociabilidade, literatura e responsabilidade intelectual na Amazônia. Belém: IAP, 2014. 
LOURO, Guacira Lopes. Gênero, sexualidade e educação: uma perspectiva pósestruturalista: Vozes, 1997.

MONTEIRO, Paula. Diversidade Cultural: Inclusão, Exclusão e Sincretismo. Belo Horizonte: Editora UFMG, 1996. 